\title{
School Teachers' Knowledge about Autism in Saudi Arabia
}

\author{
Abdulhade I. Haimour ${ }^{1, *} \&$ Yahia F. Obaidat ${ }^{1}$ \\ ${ }^{1}$ Department of Special Education, King Abdulaziz University, Saudi Arabia \\ *Corresponding author: Department of Special Education, King Abdulaziz University, Saudi Arabia \\ E-mail: haimour79@hotmail.com
}

Received: August 28, $2013 \quad$ Accepted: September 13, $2013 \quad$ Online Published: October 15, 2013

doi:10.5430/wje.v3n5p45 URL: http://dx.doi.org/10.5430/wje.v3n5p45

\begin{abstract}
The purpose of this study was to find out what school teachers know about Autism. In addition, this study attempted to find out if there any significant differences in school teachers' knowledge about Autism depending on teachers' (gender, position, education level, teaching experience, and contact with students with Autism) variables. A total of 391 general and special education teachers from various segregated and inclusive schools within the Jeddah in Saudi Arabia completed study instrument (Autism knowledge Questionnaire) to determine their level of knowledge about Autism. An analysis of the collected data, using descriptive statistics and analysis of variance, indicated that school teachers had an acceptable approaching to weak level of knowledge about Autism disorder. The results also indicated significant differences in the teachers' knowledge about Autism depending on teachers' (position, education level, teaching experience, and contact with students with Autism) favoring special education teachers, more advanced level of education and teaching experience, and those with previous contact with students with Autism.
\end{abstract}

Keywords: school teachers; knowledge; autism

\section{Introduction and Literature Review}

Autism is a pervasive developmental disorder, characterized by communication deficits, social interaction impairments, and restricted or repetitive behaviors and interests ([DSM-IV-TR]; American Psychiatric Association, 2000). Symptom of the Autism is highly heterogeneous and can range from severe impairment to mild delay (Mesibov \& Shea, 1996). Autism now affects a significant number of students in schools. It is well documented that the unique learning characteristics of these students differ widely from other learners, requiring teachers to possess specialized skills (Simpson, 2005a). Despite advancements in instructional practices for students with Autism, little attention has been given to examining the qualities of special and general education teachers who deliver services to these students in inclusive sittings (Jordan, 2005).

Between 1995 and 2008, the number of American school children receiving special education services for Autism rose from 22,000 to over 140,000 (Fredericks, 2008). The rise in reported numbers of students with Autism in public schools, poor educational outcomes, increased litigation, and an expansion of knowledge of educational practices effective with this population has led to a sense of urgency among educators and parents to ensure students are provided an appropriate education. These data present a challenge to school teachers to become better prepared to serve children with Autism, both instructionally and socially. Additionally, increasing legislative demands placing an emphasis on teacher qualities raise questions about teachers who serve students with Autism. As a result, it has become increasingly necessary to ensure school teachers are adequately prepared and possess requisite knowledge and skills. To meet the needs of the growing number of students with Autism and to take the necessary action to assist them, school teachers must become aware of Autism. Awareness of Autism is the first step in supporting and serving students with Autism. Teachers need to learn about the nature of Autism and about the needs of children with Autism. School teachers, have the capacity to change practice within the school and to affect the instruction of students with Autism. The knowledge held by the teachers is information that can create change, either by creating grounds for action or by making an individual (or institution) capable of different or more effective action (Drucker, 1989).

Because of the increasing prevalence of Autism, every public school teacher is likely to serve students with Autism. However, many teachers lack sufficient awareness, knowledge, and understanding of Autism to meet the needs of 
these students in the public schools. Little is known about what factors are associated with awareness, knowledge, and understanding of Autism among school teachers (Schwartz \& Drager, 2008).

Based on an examination of the literature, little research has evaluated qualities of teachers who serve students with Autism. It is well documented that the learning characteristics of these individuals differ widely from other learners requiring teachers to possess specialized skills (Simpson, 2005b). Research is needed to determine whether teachers possess knowledge of educational practices critical for the improvement of students with Autism, whether they implement these practices into the classroom, as well as training needs of these teachers.

Some efforts have been made to assess the knowledge base of teachers and other educational professionals about Autism. For example, Stone and Rosenbaum (1988) found that teachers held incorrect beliefs about students with Autism, particularly in the area of cognition, when compared to Autism specialists. Other studies have shown that speech-language pathologists demonstrated inadequate knowledge of strategies for inclusion (Cascella \& Colella, 2004). Furthermore, despite demonstration of accurate knowledge about Autism, medical professionals have been shown to make recommendations inconsistent with their knowledge (Kennedy, Regehr, Rosenfield, Roberts \& Lingard, 2004).

A study comparing special education teachers to general education teachers found pronounced differences between the two groups (Buell, Hallam, Gamel-McCormick \& Scheer, 1999). For example, general education teachers expressed more need for inclusion training than special education teachers. Moreover, special education teachers expressed greater confidence in performing inclusion related tasks such as adapting curricula, participating in IEP meetings, and writing behavioral objectives.

A dissertation by (Hendricks, 2007) evaluated special education teachers' knowledge and implementation of educational practices critical for the improvement of students with Autism and determined areas of training needs. A total of 498 special education teachers were surveyed, Participants reported a low to intermediate level of knowledge as well as implementation of practices. The most frequently reported was a need for training in social skills development, and the least frequently reported was training in individualization and support strategies. Relationships between the level of knowledge, implementation, and training needs and teachers' occupational characteristics were explored. Numerous occupational characteristics were found to have a relationship with level of knowledge and implementation, including area of endorsement, educational level, educational setting, number of students with Autism taught, and student learning characteristics.

It is now widely believed that teacher qualities have a significant impact on student achievement (Darling-Hammond \& Youngs, 2002). The plan embodied in the No Child Left Behind Act of 2001 (NCLB) and the Individuals with Disabilities Improvement Act (IDEA, 2004) recognized the importance of teacher quality, and as a result, set the goal that all students are taught by a "highly qualified teacher" (HQT).In a more recent study conducted by the Center on Personnel Studies in Special Education (COPSSE), Brownell, Ross, Colon and McCallum (2003) analyzed special education teacher preparation programs. They concluded special education teachers require instruction in both subject matter knowledge as well as instructional pedagogy.

Recently, a number of studies have evaluated the knowledge, practices, and training needs of professionals who work with individuals with Autism. Cascella \& Colella (2004) investigated the knowledge of Autism spectrum disorders among speech language pathologists. Eighty-two speech-language pathologists working in schools in Connecticut were surveyed. Knowledge was assessed by asking questions about behavioral characteristics, communication characteristics, related education and intervention strategies, assessment formats, and inclusion strategies. Participants reported the most knowledge in behavioral and communication characteristics associated with Autism spectrum disorders, and the least knowledge in education and intervention strategies.

Stahmer, Collings and Palinkas (2005) examined the knowledge and practices of early intervention service providers. Twenty-two early intervention specialists who worked with children with Autism under the age of five participated in focus groups. Providers reported using mostly non-evidence based techniques. Of the 30 interventions listed, only one third were evidence based. Participants reported wanting to use only those methods shown to be effective, but few had analyzed the literature on the techniques used. All providers reported concerns about adequate training and desired further information on interventions that are effective with children with Autism.

Stone and Rosenbaum (1988) examined teachers' knowledge and beliefs about Autism and found teachers had many misconceptions about the disorder. Experience with students with Autism ranged from 1-19 years. Teachers held multiple certifications, with emotional disturbance and mental retardation being the most common.

Whaley (2002) completed a dissertation surveying special education teachers who work with students with Autism in 
Tennessee. The knowledge of etiology and educational programming, the types of teaching methodologies implemented, and the training needs of teachers were evaluated. A total of 292 special education teachers working in 11 school districts in Tennessee completed surveys. On the knowledge portion of the survey, special educators were asked true false questions about etiology and educational programming. In etiology, teachers had a mean score of $73 \%$ correct. In educational programming, teachers received a mean score of $79 \%$. However, there were some similar misconceptions. Teachers inappropriately viewed Autism as an emotional disorder, despite evidence that it is neurobiological in nature. Assessment of training needs of special education teachers indicated most (77\%) wanted further training in strategies to support students with Autism. Results of this study indicated special education teachers lack an understanding of the research base regarding Autism. Most teachers desired more training in this area. However, teachers may benefit from training that will provide not only information on efficacious teaching strategies, but also provide information on evaluating research and determining treatment effectiveness.

According to (U.S. Department of Education, 2001), over 20\% of children with Autism spend most of their time in a regular education classroom. Given this rise in the mainstreaming of children with Autism, a successful teaching for this population needs for better understanding the general educators' variables affecting it (Swaim \& Morgan, 2001). Precisely, there is a shortage of literature that examines general educators' knowledge, self-efficacy, and concerns in teaching students with Autism in comparison to special educators. Additionally, little attention in assessing teacher knowledge of the characteristics of the disorder has been noted (Jennett, Harris \& Mesibov, 2003).

Direct experience in dealing with students with special needs is a critical factor in general educators' efficacy of teaching such a population and with their ability to include such students in their class (Giangreco, Dennis, Cloniger, Edelman \& Schattman, 1993). Specially, research indicates that general educators who teach children with disabilities do not have the capabilities necessary to meet the needs of these special learners (Campbell- Whatley, Obiakor \& Algozzine, 1995).

A sample of 72 educators was assessed regarding knowledge of Autism characteristics, beliefs about etiology, effective teaching practices, and teacher training needs (Helps, Newsom-Davis \& Callias, 1999). Findings revealed that teachers in mainstream schools had generally poorer knowledge of Autism and had less training than the special educators group. Teachers of both groups harbored misconceptions about the disorder including the trend not to view children with Autism as having learning difficulties (Helps et al., 1999).

Mavroupoulou and Padeliadu (2000) conducted one of the few studies that examined general educators' $(\mathrm{n}=35)$ and special educators' $(n=29)$ general knowledge of the Autism disorder and views of the instructional goals for these children. Both groups of teachers rated several problematic features of Autism (i.e., sleep, eating problems) as the least significant features of Autism. Additionally, a significant number of teachers in both groups felt that psychotherapy is an effective form of treatment for the Autism disorder. In general, special educators in this study reported more thorough knowledge of Autism and promoted instruction in all major deficit areas.

Seagal (2008) proposed the Autism Inclusion Questionnaire, to assess the constructs of experience, knowledge, attitudes towards inclusion, and classroom practices as they relate to Autism. Results indicated that education professionals $(N=47)$ reported generally positive attitudes; however, educators demonstrated important misconceptions and lack of knowledge regarding Autism. Further, a significant relationship was found between knowledge of Autism and awareness of potential classroom strategies for inclusion, whereas attitudes and awareness of strategies were unrelated.

Schwarber (2006) also examined teachers' knowledge of symptoms, concerns, and self-efficacy in teaching children with Autism. The sample of 166 preschool general education teachers $(n=105)$, special education teachers $(n=29)$, and other educational professionals (i.e., occupational therapists, and speech pathologists) attending an in-service from eleven elementary schools were selected from four school districts in the Midwest. Results indicated that there was confusion regarding Autism knowledge amongst all educators. Special educators had more knowledge, higher self-efficacy, and less concern in teaching children with Autism than general education teachers.

In summary, recent research suggests that general educators found themselves ineffectively prepared to teach children with disabilities (Sprague \& Pennell, 2000). Additionally, general educators receive limited preparation to meet the academic needs of students with disabilities, and few believed that they have sufficient time, skills, training, or resources necessary for successful inclusion. Given the increase in children being diagnosed with Autism and included in regular education classrooms (U.S. Department of Education, 2001) and the link between teacher self-efficacy, knowledge, and effective teaching (Brownell \& Pajares, 1999), more research is necessary to determine the relationship between knowledge/skill level and self-efficacy in teaching children with severe disabilities. 


\subsection{Statement of the Problem}

Autism now affects a significant number of students in schools, and this will set a challenge to school teachers to become better prepared to serve children with Autism. To meet the needs of the growing number of students with Autism and to take the necessary action to assist them, school teachers must become aware of Autism. Increasing research and literature shows that educators lack skills and knowledge of Autism and how students with Autism learn.

\subsection{Purpose of the Study}

The purpose of the study was to find out what school teachers know about Autism. Educators' knowledge or lack of knowledge of Autism could greatly affect the students and the tools to provide an appropriate education for students with Autism. In addition, this study attempted to find out if there any significant differences in school teachers' knowledge about Autism depending on the variables; teacher gender (female or male), teacher position (special or general education), teacher education level (bachelor's degree and below or master's degree and above), teaching experience (less than 5 years, 5-10 years, more than 11 years), and contact with students with Autism variables. Based on the reviewed literature, there are several research questions regarding teachers' knowledge about Autism. Specifically, this study aimed to answer the following questions:

1. What level of knowledge do school teachers possess about Autism?

2. Are there any significant differences of teachers' knowledge about Autism based on their gender, position, education level, teaching experience, and contact with students with Autism variables?

\section{Methods}

\subsection{Research Design}

This study utilized a quantitative descriptive survey research design to determine special and general education teachers knowledge about Autism in both segregated and inclusive school sittings.

\subsection{Population of Sample}

Special and regular education teachers working in both segregated and inclusive schools in Jeddahdistrict which considered as one of the biggest cities in Saudi Arabia were invited to participate in this research study. Participating teachers were asked to completeThe Autism knowledge Questionnaire (AKQ) to determine their level of knowledge about Autism. The researcher contacted the appropriate school administrators in Jeddah to obtain permission to conduct this study. Initially, the questionnaires was administered to 410 general and special education teachers; 402 of the questionnaires were completed and returned, 11 of which were excluded for providing incomplete information. Thus, the final sample consisted of 391 general and special education teachers from various segregated and inclusive schools within the Jeddah in Saudi Arabia. The teachers were randomly selected from the study population. Table (1) provides the sample distribution according to the variables of the study: gender, position, education level, teaching experience, and contact with students with Autism.

Table 1: Distribution of the Study Sample According to the Variables of the Study

\begin{tabular}{llll}
\hline Variable & & Number & Total \\
\hline position & Special education & 179 & 391 \\
& General education & 212 & \\
Gender & Female & 193 & 391 \\
\multirow{2}{*}{ Education Level } & Male & 198 & \\
& Bachelor or less & 329 & 391 \\
\multirow{2}{*}{ Teaching Experience } & Higher diploma & 41 & \\
& Master's & 21 & 391 \\
& Less than 5 years & 130 & \\
contact with students with Autism & 5-10 years & 148 & \\
& More than 10 years & 113 & \\
& Yes & 207 & 391 \\
\hline
\end{tabular}




\subsection{Measures}

The Autism knowledge Questionnaire (AKQ) was developed for the present study and contains two sections. The first section is the key demographic variables (gender, position, education level, teaching experience) and a question about previous contact or experiences with individuals with Autism. The second section, The Autism knowledge Questionnaire (AKQ), contains 30 items proposed to measure one's knowledge of Autism. The questionnaire mainly assess and measure knowledge of general information about the characteristics of students with Autism and how those students with this disorder function. Knowledge items were adapted from Stone (1987), Shah (2001), and Furnham \& Buck (2003). The questions in this section were presented as True/False statements; however, a 'Don't Know' option was included and respondents were instructed to select this response rather than guess. The face validity of the current study questionnaire was verified by a group of professors (eight professors) trained in the field of special education that rated the clarity and appropriateness of the scale statements. Based on the group's observations and suggestions, necessary adjustments were made, and some phrases were reworded. After implementing the professors suggestions, their percentage of agreement reached $87 \%$. On the other hand, the reliability for the internal consistency of the study instrument was measured by Cronbach Alpha with a value reached $(0,926)$.

\subsection{Data Collection Procedure}

After contacting the appropriate school administrators of both segregated and inclusion schools to obtain permission to conduct this study, teachers were asked to completethe Autism knowledge Questionnaire (AKQ) to determine their level of knowledge about Autism. The Data collection for the study was conducted in the summer of 2013.

\subsection{Data Analysis Procedure}

To answer the research questions, the data were analyzed using descriptive statistics for categorical data (i.e., means, standard deviations). Data were numerically coded and transferred to the statistical package for social science (SPSS) pack 20. The Autism knowledge Questionnaire (AKQ)was divided into categories of True, False and Do Not Know. A true response was coded with a score of 1 , a False response was coded with a score of 0 , and a score of 0 was used for do not know. Teachers lake of knowledge was measured by the number of incorrect responses and don't know responses on the (AKQ). Responses of the study sample members were calculated by extracting the (percentage and mean) of the correct responses for each member of the sample on the Autism knowledge Questionnaire (AKQ). If the mean of correct responses of a particular sample member were above (0.7), their knowledge about Autism was considered 'Good'; If the mean ranged between (0.5 - 0.7), their knowledge about Autism was considered 'Acceptable'; and if the mean was below (0.5), their knowledge was considered 'Weak'. Higher mean scores indicated better knowledge about Autism, and lower mean scores indicated weaker knowledge about Autism.

And finally, to measure the relationship between several independent variables (gender, position, education level, teaching experience, and contact with students with Autism) and one dependent variable (teachers knowledge about Autism), a multivariate analysis (ANOVA) and Post hoc analysis (Scheffe) tests were used.

\section{Results}

The first research question pertaining to this study aimed to find out what school teachers know about Autism. Teachers, level of knowledge was measured by The Autism knowledge Questionnaire (AKQ). Table 2 shows numbers and percentages of the correct answers that both special and general school teachers have achieved on the (AKQ). Here we notice that all correct answers on the study tool ranged between $(42.7 \%-74.9 \%)$. Items $(1,4,9,13$, 23,26 , and 29) were below (50\%), and items $(6,7,10,12,17,19,22,24$, and 27$)$ were between $(50 \%-60 \%)$. This gives a hint around the lake of knowledge that school teachers had about Autism disorder. 
Table 2: Mean, Std., Number, and Percentage of Correct Answers for Each Item of the Questionnaire for All Study Sample

\begin{tabular}{|c|c|c|c|c|c|}
\hline \multirow[b]{2}{*}{ Item N. } & \multirow[b]{2}{*}{ item } & \multicolumn{2}{|c|}{ Correct answers } & \multirow[b]{2}{*}{ Mean } & \multirow[b]{2}{*}{ Std. } \\
\hline & & number & Percentage & & \\
\hline 1 & Most children with Autism have an intellectual disability & 190 & 48.6 & .49 & .500 \\
\hline 2 & $\begin{array}{l}\text { Autism disorder is usually diagnosed during the first three } \\
\text { years of the child's age }\end{array}$ & 258 & 66.0 & 66 & .474 \\
\hline 3 & $\begin{array}{l}\text { Children with Autism usually manifest special abilities like } \\
\text { drawing and facts and figures remembering }\end{array}$ & 274 & 70.1 & .70 & .459 \\
\hline 4 & $\begin{array}{l}\text { Children must exhibit impaired social interaction and } \\
\text { language communication to be diagnosed with Autism }\end{array}$ & 192 & 49.1 & .49 & .501 \\
\hline 5 & Autism is a developmental disorder & 236 & 60.4 & .60 & .490 \\
\hline 6 & $\begin{array}{l}\text { With proper intervention, most children with Autism disorder } \\
\text { will eventually "outgrow" the disorder }\end{array}$ & 197 & 50.4 & .50 & .501 \\
\hline 7 & most autistic children do not talk & 220 & 56.3 & .56 & .497 \\
\hline 8 & The majority of children with Autism are female & 248 & 63.4 & .63 & .482 \\
\hline 9 & $\begin{array}{l}\text { Children with Autism do not make any visual communication } \\
\text { during conversation with others }\end{array}$ & 189 & 48.3 & .48 & .500 \\
\hline 10 & $\begin{array}{l}\text { Most children with Autism have a problem with imaginary } \\
\text { playing }\end{array}$ & 212 & 54.2 & .54 & .499 \\
\hline 11 & $\begin{array}{l}\text { Some children with Autism have high or low sensitivity of } \\
\text { visual, auditory, tactile, or olfactory stimuli }\end{array}$ & 261 & 66.8 & 67 & .472 \\
\hline 12 & Autism disorder is diagnosed by medical methods & 197 & 50.4 & .50 & .501 \\
\hline 13 & Behavioral patterns in children with Autism are similar & 190 & 48.6 & .49 & .500 \\
\hline 14 & $\begin{array}{l}\text { We can diagnose Autism disorder depending on physical } \\
\text { features }\end{array}$ & 243 & 62.1 & .62 & .486 \\
\hline 15 & $\begin{array}{l}\text { Behavioral intervention is considered the most effective } \\
\text { treatment method of Autism }\end{array}$ & 293 & 74.9 & .75 & .434 \\
\hline 16 & In many cases, the cause of Autism disorder is unknown & 244 & 62.4 & .62 & .485 \\
\hline 17 & Children with Autism tend to be auditory learners & 214 & 54.7 & .55 & .498 \\
\hline 18 & $\begin{array}{l}\text { Some children with Autism demonstrate inconsistency in } \\
\text { motor skills }\end{array}$ & 242 & 61.9 & .62 & .486 \\
\hline 19 & Poor parenting practices can cause Autism disorder & 234 & 59.8 & .60 & .491 \\
\hline 20 & $\begin{array}{l}\text { children with Autism behave better only in organized } \\
\text { educational environments }\end{array}$ & 268 & 68.5 & .69 & .465 \\
\hline 21 & $\begin{array}{l}\text { If a particular method of treatment achieved effective results } \\
\text { with some children with Autism, then it is necessarily } \\
\text { effective with all children with Autism }\end{array}$ & 239 & 61.1 & .61 & .488 \\
\hline 22 & Autism could be associated with Epilepsy & 211 & 54.0 & .54 & .499 \\
\hline 23 & Autistic children prefer routine activities & 179 & 45.8 & .46 & .499 \\
\hline 24 & Child with Autism appears like a deaf & 231 & 59.1 & .59 & .492 \\
\hline 25 & $\begin{array}{l}\text { Autism disorder can be diagnosed through behavioral } \\
\text { observation }\end{array}$ & 270 & 69.1 & .69 & .463 \\
\hline 26 & $\begin{array}{l}\text { Medication can alleviate the core symptoms of Autism } \\
\text { disorder }\end{array}$ & 192 & 49.1 & .49 & .501 \\
\hline 27 & $\begin{array}{l}\text { Genetic factors play an important role as a cause of Autism } \\
\text { disorder }\end{array}$ & 204 & 52.3 & .52 & .500 \\
\hline 28 & Children with Autism frequently repeat the talk they hear & 243 & 62.1 & .62 & .486 \\
\hline 29 & $\begin{array}{l}\text { Generally, children with Autism understand feelings and } \\
\text { emotions of others. }\end{array}$ & 167 & 42.7 & .43 & .495 \\
\hline 30 & $\begin{array}{l}\text { Children with Autism demonstrate stereotypical behaviors } \\
\text { like fluttering }\end{array}$ & 268 & 68.5 & .69 & .465 \\
\hline & Total level of knowledge & & & .58 & .275 \\
\hline
\end{tabular}


Moreover, means and standard deviations for responses of school teachers on each item of the questionnaire and for the whole level of knowledge were extracted. Table 2 indicates that the mean ranged from $(0.43-0.75)$, and the mean value of total level of knowledge that school teachers had about Autism disorder was (0.58) that lies between ( 0.5 - 0.7), which suggests that general and special education school teachers had an acceptable approaching to weak level of knowledge about the Autism disorder.

The second aim of this research was to investigate the potential differences in school teachers' knowledge about the Autism with respect to teachers' gender, position, education level, teaching experience, and contact with students with Autism. To address this aim, two processes of analysis were implemented; initially, means, standard deviation, and Results of T-test for the teachers responses depending on (Gender, Position, and Contact with student with Autism) variables were extracted as shown in Table 3.

Table 3: Means, Std., and Results of T-test for the Teachers Responses Depending on (Gender, Position, and Contact with student with Autism) variables

\begin{tabular}{llcccccc}
\hline Variables & & $\mathrm{N}$ & Mean & Std. & $\mathrm{T}$ & $\mathrm{df}$ & Sig. \\
\hline Gender & Male & 198 & .59 & .294 & & & \\
& Female & 193 & .57 & .254 & .395 & 389 & .693 \\
position & Special education & 179 & .83 & .128 & 28.526 & 389 & .000 \\
& General education & 212 & .37 & .177 & & & \\
contact with students with Autism & Yes & 207 & .78 & .179 & 24.019 & 389 & .000 \\
& No & 184 & .36 & .169 & & & \\
\hline
\end{tabular}

As shown in Table 3, the mean scores differ based on the gender (male and female) of the respondent. The male group ( $\mathrm{n}=198)$ had a mean of $\overline{\mathrm{x}}=0.59$ and a standard deviation of $\sigma=0.294$; the female group $(\mathrm{n}=193)$ had a mean of $\overline{\mathrm{x}}=0.57$ and a standard deviation of $\sigma=0.254$. A T-test between the means yielded $\mathrm{t}(389)=0.395$ at $\mathrm{p}=0.693$, for $\mathrm{p} \geq 0.05$. Thus, no significant differences were found in the means among the gender groups. The findings thus indicated that responses were independent of gender variable. For the second variable, differences in the mean scores were found based on the teacher position (special education teacher or general education teacher), as shown in Table 3. The special education teachers group $(\mathrm{n}=179)$ had a mean score of $\overline{\mathrm{x}}=0.83$ and a standard deviation of $\sigma=$ 0.128; whereas the general education group (212) had a mean score of $\overline{\mathrm{X}}=0.37$ and a standard deviation of $\sigma=$ 0.177 . A T-test between the means yielded $t(398)=28.526$ at $\mathrm{p}=0.000$, for $\mathrm{p} \geq 0.05$. These results indicate a statistically significant difference between the means of the special education teachers and the general education teachers groups, and that the special education teachers group had a higher level of knowledge about the Autism than general education teachers group.

Regarding the third variable, as shown in Table 3, differences in the mean scores were found based on thecontact with students with Autism. Teachers who had a previous contact with students with Autism $(n=207)$ had a mean score of $\overline{\mathrm{x}}=0.78$ and a standard deviation of $\sigma=0.179$; whereas Teachers who had no previous contact with students with Autism $(n=184)$ had a mean score of $\overline{\mathrm{x}}=0.36$ and a standard deviation of $\sigma=0.169$. A T-test between the means yielded $t(398)=24.019$ at $p=0.000$, for $\mathrm{p} \geq 0.05$. These results indicate a statistically significant difference between the means of the teachers who had a previous contact with students with Autism and the teachers who had no previous contact with students with Autism. And that the teachers who had a previous contact with students with Autism group had a higher level of knowledge about the Autism than those who had no previous contact with students with Autism.

For the purpose of investigating the potential differences in school teachers' knowledge about the Autism with respect to teachers' education level and teaching experience, another processes of analysis were implemented. Regarding the differences between school teachers' knowledge about the Autism with respect to teachers' education level, as shown in Table 4, differences in the mean scores were found. Teachers who had a Bachelor degree $(\mathrm{n}=329)$ had a mean score of $\overline{\mathrm{X}}=16.35$ and a standard deviation of $\sigma=0.626$; and teachers who had a Higher Diploma degree $(n=41)$ had a mean score of $\overline{\mathrm{x}}=20.27$ and a standard deviation of $\sigma=0.702$; and teachers who had Master degree $(\mathrm{n}=21)$ had a mean score of $\overline{\mathrm{x}}=28.38$ and a standard deviation of $\sigma=0.673$. An ANOVA test between the means yielded $(\mathrm{F}=26.957)$ at $\mathrm{p}=0.000$, for $\mathrm{p}<0.05$. These results indicate a statistically significant difference between the means of the different education level groups. 
Table 4: Means, Std., and Results of Analysis of Variance (ANOVA) for the Teachers Responses Depending on (Education level and Experience) Variables

\begin{tabular}{|c|c|c|c|c|c|c|c|c|c|c|}
\hline variable & & $\mathrm{N}$ & Mean & Std. & & $\begin{array}{l}\text { Sum of } \\
\text { squares }\end{array}$ & $\mathrm{df}$ & $\begin{array}{l}\text { Mean } \\
\text { squares }\end{array}$ & $\mathrm{F}$ & Sig. \\
\hline \multirow[t]{3}{*}{ Education } & Bachelor & 329 & 16.35 & .626 & Between G. & 3232.5 & 2 & 1616.1 & 26.957 & .000 \\
\hline & Diploma & 41 & 20.27 & .702 & Within G. & 23263.8 & 388 & 59.95 & & \\
\hline & Master & 21 & 28.38 & .673 & Total & 26496.3 & 390 & & & \\
\hline \multirow[t]{3}{*}{ Experience } & $<5$ & 130 & 19.26 & 7.998 & Between G. & 1145.6 & 2 & 572.78 & 8.767 & .000 \\
\hline & $5-10$ & 148 & 17.66 & 8.146 & Within G. & 25350.8 & 388 & 65.337 & & \\
\hline & $>10$ & 113 & 14.94 & 8.098 & Total & 26496.3 & 390 & & & \\
\hline
\end{tabular}

In addition, A Scheffé post hoc test was conducted for the comparisons between different education level groups as shown in Table 5. Results indicated that teachers with Higher diploma had higher level of knowledge about Autism in comparison with teachers with Bachelor degree (mean difference $=-3.92$ at $\mathrm{p}=0.010$ ), and teachers with Master degreehad higher level of knowledge about Autism in comparison with teachers with Bachelor degree (mean difference $=-12.03$ at $p=0.000$ ), and finally, teachers with Master degree had higher level of knowledge about Autism in comparison with teachers with Higher diploma degree (mean difference $=8.11$ at $\mathrm{p}=0.001$ ).

Table 5: Post Hoc Analysis (Scheffee test) for the Teachers Responses Depending on (Education level, and Experience) Variables

\begin{tabular}{llccc}
\hline Variables & & & & \\
Education Level & & Mean Difference & Std. Error & Sig \\
\hline Bachelor & High Diploma & $-3.92\left(^{*}\right)$ & 1.282 & .010 \\
& Master & $-12.03\left(^{*}\right)$ & 1.743 & .000 \\
High Diploma & Bachelor & $3.92\left(^{*}\right)$ & 1.282 & .010 \\
& Master & $-8.11\left(^{*}\right)$ & 2.078 & .001 \\
Master & Bachelor & $12.03\left(^{*}\right)$ & 1.743 & .000 \\
& High Diploma & $8.11\left(^{*}\right)$ & 2.078 & .001 \\
Experience & & & & \\
Less than 5 years & 5-10 years & 1.60 & .972 & .259 \\
& More than 10 years & $4.32\left(^{*}\right)$ & 1.040 & .000 \\
5-10 years & Less than 5 years & -1.60 & .972 & .259 \\
\multirow{2}{*}{ More than 10 years } & More than 10 years & $2.72\left(^{*}\right)$ & 1.010 & .027 \\
& Less than 5 years & $-4.32\left(^{*}\right)$ & 1.040 & .000 \\
& 5-10 years & $-2.72\left(^{*}\right)$ & 1.010 & .027 \\
\hline
\end{tabular}

Regarding the differences between school teachers' knowledge about the Autism with respect to teachers' Experience variable, as shown in Table 4, differences in the mean scores were found. Teachers with $(<5)$ years of experience ( $\mathrm{n}=130)$ had a mean score of $\overline{\mathrm{x}}=19.26$ and a standard deviation of $\sigma=7.998$; and teachers with (5-10) years of experience $(\mathrm{n}=148)$ had a mean score of $\overline{\mathrm{x}}=17.66$ and a standard deviation of $\sigma=8.146$; and teachers with $(>10)$ years of experience $(n=113)$ had a mean score of $\bar{x}=14.94$ and a standard deviation of $\sigma=8.098$. An ANOVA test between the means yielded $(\mathrm{F}=8.767)$ at $\mathrm{p}=0.000$, for $\mathrm{p}<0.05$. These results indicate a statistically significant difference between the means of the different teachers' Experience level groups. In addition, A Scheffé post hoc test was conducted for the comparisons between different teachers' Experience level groups as shown in Table 5. Results indicated that teachers with $(<5)$ years of experience had higher level of knowledge about Autism in comparison with teachers with $(>10)$ years of experience (mean difference $=4.32$ at $p=0.000$ ), and teachers with (5-10) years of experience had higher level of knowledge about Autism in comparison with teachers with $(>10)$ years of experience (mean difference $=2.72$ at $\mathrm{p}=0.027$ ). 


\section{Discussion}

The purpose of the study was to find out what school teachers know about Autism. In addition, this study attempted to find out if there any significant differences in school teachers' knowledge about Autism depending on the variables; teacher gender, teacher position, teacher education level, teaching experience, and contact with students with Autism variables. The first research question indicated a lake of knowledge that school teachers had about Autism disorder, as the mean value of total level of knowledge that school teachers had about Autism disorder was $(0.58)$ and lied between $(0.5-0.7)$, which suggests that general and special education school teachers had an acceptable approaching to weak level of knowledge about the Autism disorder. taking into consideration the result that special education teachers group had a mean score of $\overline{\mathrm{X}}=0.83$ and the general education group had a mean score of $\overline{\mathrm{x}}=0.37$, leads us to the finding that, specifically, general education teacher had a weak knowledge about Autism, and special education teachers had relatively good level of knowledge about Autism. This result may be related to fact that general school teachers are not prepared well to deal with student with Autism, and a lake of proper in-service inclusion training programs for those teachers.

This result was confirmed by Jordan (2005) study, indicated that little attention has been given to examining the qualities of special and general education teachers who deliver services to these students in inclusive sittings. Moreover, Drucker (1989) claimed that increasing legislative demands placing an emphasis on teacher qualities, raise questions about teachers who serve students with Autism. As a result, it has become increasingly necessary to ensure school teachers are adequately prepared and possess requisite knowledge and skills. To meet the needs of the growing number of students with Autism and to take the necessary action to assist them, school teachers must become aware of Autism. Teachers need to learn about the nature of Autism and about the needs of children with Autism. School teachers, have the capacity to change practice within the school and to affect the instruction of students with Autism. Stone and Rosenbaum (1988) also found that teachers held incorrect beliefs about students with Autism, particularly in the area of cognition, when compared to Autism specialists.

In addition, results of this current study are in agreement with a descriptive study about knowledge, practices employed, and training needs of special education teachers serving students with Autism by Hendricks (2007), in which participants reported a low to intermediate level of knowledge as well as implementation of practices. The most frequently reported was a need for training in social skills development. Numerous occupational characteristics were found to have a relationship with level of knowledge including; area of endorsement, educational level, educational setting, number of students with Autism taught, and student learning characteristics.

Results of the second study objective aimed to find out if there any significant differences in school teachers' knowledge about Autism depending on the variables; teacher gender, teacher position, teacher education level, teaching experience, and contact with students with Autism variables. These results did not indicate any significant differences in teachers' knowledge depending on teachers' gender. With regard to teacher position variable, results indicated that special education teachers group had a higher level of knowledge about Autism than general education teachers group.This finding is in agreement with a study comparing special education teachers to general education teachers in relation to knowledge about Autism by Buell et al. (1999) in which general education teachers expressed more need for inclusion training than special education teachers. Moreover, special education teachers expressed greater confidence in performing inclusion related tasks such as adapting curricula, participating in IEP meetings, and writing behavioral objectives.

Regarding the teacher education level variable, results indicated that teachers with Higher diploma had higher level of knowledge about Autism in comparison with teachers with Bachelor degree, and teachers with Master degree had higher level of knowledge about Autism in comparison with teachers with Bachelor degree, and finally, teachers with Master degree had higher level of knowledge about Autism in comparison with teachers with Higher diploma degree. Teachers with advanced education levels like those with master degree, may have received more advanced courses In the field of education and specifically special education.Teaching in the Master's stage is often more comprehensive and deeper than teaching in the Bachelor stage. Moreover, teaching methods might be different and depend on research and scientific investigation, which increases the level of teachers' knowledge about this topic.This finding is in agreement with (Hendricks, 2007) study that found numerous occupational characteristics (one of them is the educational level) had a relationship with level of knowledge about Autism.

With regard to teaching experience variable, findings indicated that teachers with $(<5)$ years of experience had higher level of knowledge about Autism than teachers with $(>10)$ years of experience, and teachers with (5-10) years of experience had higher level of knowledge about Autism in comparison with teachers with $(>10)$ years of experience. This result may be due to the fact that people with years of experience between 1-5 years and 6-10 years 
are still at the beginning of their work and they still retain the information they received in undergraduate period. Moreover, they may still have motivation for issues relating to their students especially that their students are included in regular schools.

Finally, regarding contact with students with Autism variable, results indicated that teachers who had a previous contact with students with Autism group had a higher level of knowledge about the Autism than those who had no previous contact with students with Autism. It is a logical result, teachers who had previously deal with students with Autism through their learning and training, or that they had received courses or training sessions in the field of Autism, or that they had a self-reading about Autism, it would be necessarily that they have a more advanced level of knowledge than those who do not did exposed to such experiences. This result was confirmed by (Giangreco et al., 1993) study indicating that direct experience in dealing with students with special needs is a critical factor in general educators' efficacy of teaching such a population and with their willingness to include such students in their class. Other studies also confirmed this results indirectly by stressing on the need for teachers to have more training course around how to deal with a student with Autism in an inclusive sittings (Stahmer et al. 2005; Brownell et al. 2003; Whaley, 2002).

\section{Conclusion}

The information discussed thus far leads to the following conclusions; school teachers have relatively a lake of knowledge about Autism. This finding support the importance of professional development, and training of educators in the nature and needs of students with Autism. Different variables such as teachers' (position, education level, experience, and contact with students with Autism) were found to have a significant direct effect on the level of teachers knowledge about the Autism. School teachers who serve students with Autism in inclusive sittings present with a wide array of characteristics and qualifications. All School teachers, regardless of specific qualifications, should receive training in educational practices needed to effectively serve this group of students.General education teacher programs are sorely in need of more special education classes regarding children with exceptionalities as its focus. More research on the general education teachers' skill and knowledge level of teaching the special needs population as well as additional research on the benefits of special education/general education co-teaching of classes would aid in the development of effective mainstreaming practices.

\section{References}

American Psychiatric Association. (2000). Diagnostic and statistical manual of mental disorders (4th ed., Text revision). Washington, DC: Author.

Brownell, M.T., \& Pajares, F. (1999). Teacher efficacy and perceived success in Mainstreaming students with learning and behavior problems. Teacher Education and Special Education, 22(3), 154-164. http://dx.doi.org/10.1177/088840649902200303

Brownell, M.T., Ross, D.R., Colon, E.P., \& McCallum, C.L. (2003). Critical features of special education teacher preparation: A comparison with exemplary practices in general teacher education. (COPSSE Document Number RS-4E). Gainesville, FL: University of Florida, Center on Personnel Studies in Special Education. Retrieved from http://www.copsse.org

Buell, M., Hallam, R., Gamel-McCormick, M., \& Scheer, S. (1999). A survey of general and special education teachers' perceptions and in-service needs concerning inclusion. International Journal of Disability, Development, and Education, 46(2), 143-156. http://dx.doi.org/10.1080/103491299100597

Cambell-Whatley, G., Obiakor, F., \& Algozzine, B. (1995). Perceptions of competencies for including students with disabilities in elementary and secondary school classrooms. Special Services in the Schools, 10(1), 79-93. http://dx.doi.org/10.1300/J008v10n01_05

Cascella, P. W., \& Colella, C. S. (2004). Knowledge of autism spectrum disorders among Connecticut school speech-language pathologists. Focus on Autism and Other Developmental Disabilities, 19(4), 245-252. http://dx.doi.org/10.1177/10883576040190040601

Darling-Hammond, L., \& Youngs, P. (2002). Defining "highly qualified teachers": What does "scientifically-based research" actually tell us? Educational Researcher, 31(9), 13-25. http://dx.doi.org/10.3102/0013189X031009013 
Drucker, P. F. (1989). The new realities. New York: Harper \& Row.

Fredericks, C. (Ed.). (2008). Perspectives on diseases and disorders: autism. Detroit: Gale Cengage Learning.

Furnham, A., \& Buck, C. (2003). A comparison of lay-beliefs about autism and obsessive-compulsive disorder. International Journal of Social Psychiatry, 49(4), 287-307. http://dx.doi.org/10.1177/0020764003494006

Giangreco, M., Dennis, R., Cloniger, C., Edelman, S., \& Schattman, R. (1993). 'I've counted Jon:' Transformational experiences of teachers educating students with disabilities. Exceptional Children, 59(4), 359-372. Retrieved from ERIC database (EJ459583)

Helps, S., Newsom-Davis, I., \& Callias, M. (1999). Autism: A teachers' view. Autism, 3(3), 287-298. http://dx.doi.org/10.1177/1362361399003003006

Hendricks, D. R. (2007). A descriptive study of special education teachers serving students with autism: Knowledge, practices employed, and training needs (Doctoral dissertation). Available from ProQuest Dissertations \& Theses database. (UMI NO. 3288685)

Individuals with Disabilities Education Improvement Act of 2004, PL 105-17, 111 U.S.C. Retrived from http://idea.ed.gov

Jennet, H., Harris, S., \& Mesibov, G. (2003). Commitment to philosophy, teacher efficacy, and burnout among teachers of children with autism. Journal of Autism and Developmental Disorders, 33(6), 583-593. http://dx.doi.org/10.1023/B:JADD.0000005996.19417.57

Jordan, R. (2005). Managing autism and Asperger's syndrome in current educational provision. Pediatric Rehabilitation, 8(2), 104-112.

Kennedy, T., Regehr, G., Rosenfield, J., Roberts, S. W., \& Lingard, L. (2004). Exploring the gap between knowledge and behavior: A qualitative study on clinician action following an educational intervention. Academic Medicine : Journal of the Association of American Medical Colleges, 79(5), 386-393. http://dx.doi.org/10.1097/00001888-200405000-00006

Mavropoulou, S., \& Padeliadu, S. (2000). Greek teachers' perceptions of autism and implications for educational practice: A preliminary analysis. Autism: The International Journal of Research and Practice, 4(2), 173-183. http://dx.doi.org/10.1177/1362361300004002005

Mesibov, G., \& Shea, P. (1996). Full inclusion and students with autism. Journal of Autism and Developmental Disorders, 26(3), 337-346. http://dx.doi.org/10.1007/BF02172478

No Child Left Behind Act of 2001, 20 U.S.C. Available from http://www.ed.gov

Schwarber, L. A. (2006). A comparison of general education and special education teachers' knowledge, self-efficacy, and concerns in teaching children with Autism (Doctoral dissertation, Miami University). Retrieved from https://etd.ohiolink.edu

Schwartz, H., \& Drager, K. D. R. (2008). Training and knowledge in autism among speech language pathologists: A survey. Language, Speech, and Hearing Services in Schools, 39(1), 66-77. http://dx.doi.org/10.1044/0161-1461(2008/007)

Scruggs, T., \& Mastropieri, M. (1996). Teacher perceptions of mainstreaming/inclusion, 1958-1995: A research synthesis. Exceptional Children, 63(1), 59-74.

Segall, M. (2008). Inclusion of students with autism spectrum disorder: Educator experience, knowledge, and attitudes ( master's thesis, University of Georgia). Retrieved from http://athenaeum.libs.uga.edu

Shah, K. (2001). What do medical students know about autism? Autism, 5(2), 127-133. http://dx.doi.org/10.1177/1362361301005002003

Simpson, R. L. (2005a). Autism Spectrum Disorders: Interventions and Treatments for Children and Youth. Thousand Oaks, CA: Corwin Press.

Simpson, R. L. (2005b). Evidence-based practices and students with autism spectrum disorders. Focus on Autism and Other Developmental Disabilities, 20(3), 140-149. http://dx.doi.org/10.1177/10883576050200030201

Sprague, M.M., \& Pennell, D.P. (2000). The power of partners: Preparing pre service teachers for inclusion. The Clearing House, 73(3), 168-170. http://dx.doi.org/10.1080/00098650009600940

Stahmer, A. C., Collings, N. M., \& Palinkas, L. A. (2005). Early intervention practices for children with autism: 
Descriptions from community providers. Focus on Autism and Other Developmental Disabilities, 20(2), 66-79. http://dx.doi.org/10.1177/10883576050200020301

Stone, W. L. (1987). Cross-disciplinary perspectives on autism. Journal of Pediatric Psychology, 12(4), 615-630. http://dx.doi.org/10.1093/jpepsy/12.4.615

Stone, W. L., \& Rosenbaum, J. L. (1988). A comparison of teacher and parent views of autism. Journal of Autism and Developmental Disorders, 18(3), 403-414. http://dx.doi.org/10.1007/BF02212195

Swaim, K. F., \& Morgan, S. B. (2001). Children's attitudes and behavioral intentions toward a peer with autistic behaviors: Does a brief educational intervention have an effect? Journal of Autism and Developmental Disorders, 31(2), 195-205. http://dx.doi.org/10.1023/A:1010703316365

U.S. Department of Education, Office of Special Education and Rehabilitative Services (2001). 23nd Annual Report to Congress on the Implementation of the Individuals with Disabilities Education Act. Retrieved from http://nces.ed.gov/programs/coe/2002/pdf/28_2002

Whaley, C.H. (2002). Special education teachers' and speech therapists' knowledge of autism spectrum disorder ( doctoral dissertation, East Tennessee State University). Retrieved from http://dc.etsu.edu 